chapters, which deal with the relationship between language and intelligence in human beings and the evolution of the brain and intelligence, include an analysis and critique of the studies of language and communication in non-human animals and their relationship to human and animal intelligence.

This final section also contains the author's evaluation of the current state of knowledge of comparative studies of the brain and intelligence, which he characterizes in two working hypotheses to be tested by future research. The first is that, with the exception of human beings, neither qualitative nor quantitative differences in intelligence exist between vertebrate species; the second, that the capacity for language so affects the human's approach to problems of all kinds that the result is a qualitative difference in intelligence between humans and nonhuman vertebrates. Moreover, the influence of language is so pervasive in human reasoning that one may be unable to assess the role of non-linguistic reasoning in humans for comparison with non-human animal intelligence. These hypotheses are refreshing departures from conventional wisdom and will be the basis for considerable discussion.

While there is much to commend in the book, the treatment of certain topics falls short of perfection. For example, the only region of the brain that is discussed consistently is the forebrain and then usually only the telencephalon. Macphail justifies this emphasis by pointing out that it is this region that appears to undergo the greatest growth and development in evolution. Although his point is well taken, critics could argue that the telencephalon does not function in isolation and has important connections with the diencephalon and mesencephalon; moreover, to ignore the role of the mesencephalon in processing information about the spatial properties of the external environment may be to disregard an important aspect of the brainintelligence problem.

Another area that may disappoint some readers is Macphail's limitation of his account to certain types of formal laboratory studies of learning. Phenomena such as tool-use and learning by imitation are not discussed, the vast ethological literature and its implications for assessing the nature of animal intelligence being specifically excluded. Macphail makes a case for the latter omission, but I suspect that readers with an ethological bent may not be fully convinced.

Such disappointment as the reader might feel will nonetheless be soothed by the wealth of well-organized information, original interpretations and challenging ideas presented in this volume. I recommend it highly to anyone with a serious interest in the brain and intelligence.

\title{
View of Kew from the inside
}

\section{S.M. Walters}

Kew: Gardens for Science and Pleasure. Edited by F.N. Hepper. Pp.195. ISBN 0-11-241181-9. (HMSO/Stemmer House: 1982.) £9.95, $\$ 24.95$.

THIS handsome and lavishly illustrated book consists of a series of essays by sixteen past and present members of the staff of the Royal Botanic Gardens under the editorship of Nigel Hepper, himself a senior taxonomist in the Kew herbarium. The subject-matter covers all three parts of the Kew empire, namely: the public gardens themselves; the herbarium and other research institutions not normally visited by the public; and Wakehurst Place, the magnificent "satellite" garden in Sussex, which became part of Kew in 1965.

The introduction explains that the essays "are intended to convey a broad view of Kew's history and the horticultural and scientific work that have given the Gardens their world-wide reputation', Ray Desmond, formerly Chief Librarian at Kew, contributes the first chapter, which sketches the history of the Royal Gardens, and the remaining essays are grouped into three sections: "Gardens for Pleasure" (3 chapters); "Living Botanical Collections", (9 chapters); and "Botanical Research"

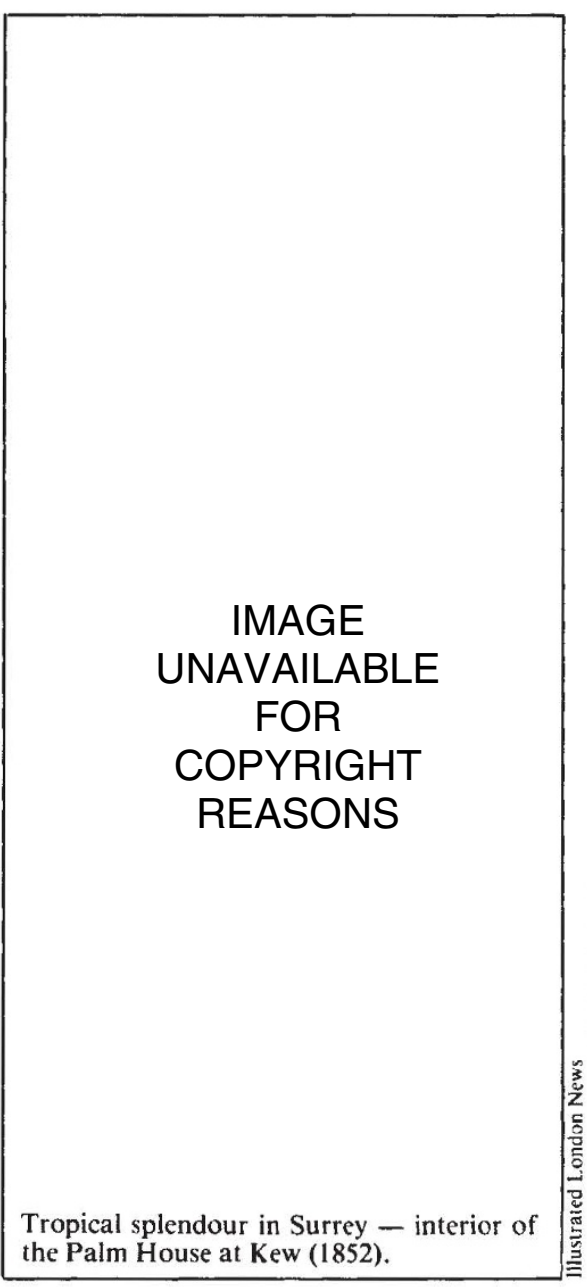

(7 chapters). The decision to integrate Wakehurst with the "old Kew" by devoting chapters to the new garden in each of the main sections, though logical, has not been entirely successful; in particular, the description of the memorial garden to Sir Henry Price, last private owner of Wakehurst, seems out of place in the first section.

A welcome feature of the book is the treatment of aspects of Kew as a botanical research establishment. Chapter 17, devoted to multidisciplinary studies of Crocus, represents a brave attempt by no fewer than five staff members to explain at a popular level mysteries such as cytotaxonomy: fortunately, the genus lends itself to attractive colour photography! Another important chapter deals with Kew's new, explicit conservation role, the most urgent of all its tasks in face of the threat to the world's flora.

Reading the essays produces a strong impression that the authors are all loyal Kew people. A measure of how parochial their view is can be obtained by looking up other botanical gardens in the index: for example, Edinburgh, by any standards one of the world's most important scientific gardens, gets only a single, oblique reference, on page 31. Even in those few areas where the outside world has dared to question the morality of Kew's activities such as the manner of acquisition of stocks of rubber plants in South America a century ago - the loyal Kew man says only (p.131): “. . popular accounts indicating that Wickham dishonestly smuggled out the Hevea seeds are unfair both to the collector and to Kew". At least a strong antidote to such sycophantic writing is available (if in very extreme form) in the recent study by Lucile Brockway (1979) cited in the select bibliography at the back of the volume. Kew still awaits a good, definitive study, preferably by a reasonably sympathetic and well-informed outsider, who can ask questions about policy and aims such as are hardly touched on in this work, even in the interesting final essay on "Kew in the Future" contributed by the retired Director, Professor Brenan.

The world of book publishing presents increasingly baffling questions to the layman. Just at the time when we are told that Her Majesty's Stationery Office will no longer subsidize official publications of any kind, that same Office publishes such a lavish, popular book as this at a price which implies a large subsidy or great optimism and an enormous print run. Whatever the explanation, we can only express our appreciation, and wish the venture success. University Press, 1981). 